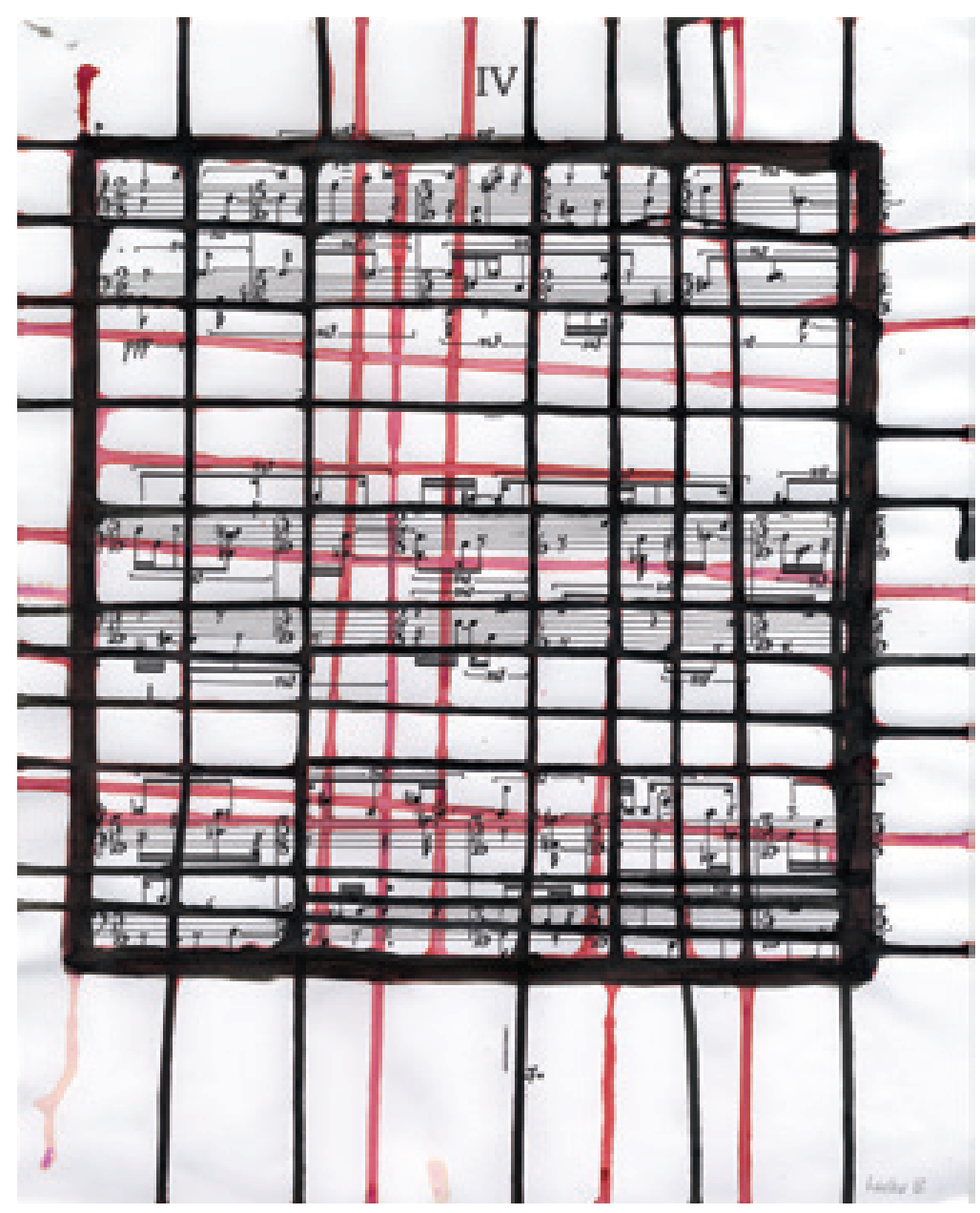

(C) Mike Walker 2013 


\title{
Listening through Morton Feldman's Triadic Memories
}

\author{
Bryn Harrison
}

What follows are my own personal reflections on Morton Feldman's 1981 extended solo piano composition Triadic Memories. The text is based on the 17 pages of notes that I made in the early hours of $16^{\text {th }}$ August 2013 whilst reflecting closely on Aki Takahashi's performance of the work (ALM Records - ALCD-33, 1989) through headphones. There are several other recorded versions that I could have used, such as those by Louis Goldstein, Roger Woodward and the two editions of Jean-Luc Fafchamps. As with other extended late works by Feldman slight variations in tempo can lead to recordings that vary considerably in length. At just over an hour, Takahashi's recording is somewhat shorter than most, (especially when compared with the Goldstein version, which lasts over 1 hour 52 minutes), but my choice was informed by Takahashi's tone, rhythmic consistency and articulation of phrases. (The second recording by Fafchamps is also, in my opinion, quite excellent in this respect but was not available to me at the time of writing.)

Whilst listening to the piece and making notes, I resisted the temptation to pause the CD player and did not refer to the score until I started to write up my notes the following day. As a result, there were times when the chronology of events became confused or where my descriptions of the materials differed slightly from what was indicated in the score. There were also occasions, perhaps adding up to a few minutes, when I found myself unable to write at all, immersed in the experience of pure listening. These hesitations and seeming contradictions have been preserved, wherever possible, in the completed text below, since a far from clear account of the work could be considered integral to Feldman's attempt to consciously disorientate the listener. I did allow myself the liberty, however, of re-writing certain phrases or passages that appeared inarticulate or unintelligible, and added to the original script where I felt there was room to describe what I had experienced in more detail. For instance, my original notes made reference to Merleau-Ponty's 
phenomenological views on time but my speculations were brief and needed to be re-examined and expanded upon for this final version. I have since made further minor revisions to the text as a whole (including adding a ferw pitch indications from the score), but hopefully have managed to preserve my thoughts and feelings from what now seems like a rather intense hour or so of listening. Needless to say, I felt it necessary to avoid expanding upon the text by going back and listening to the piece again. The 'of the moment' aspect of that initial listening experience was something that seemed essential to preserve if I was to capture some of the integrity of what Feldman brings to the compositional act itself.

I am not sure that I am the 'ideal' Feldman listener. I know the late pieces well and so my judgement is inevitably coloured by my understanding of other works from this period as well as my knowledge of Triadic Memories itself. Also, at the time of writing I am engaged in research into extended duration in experimental works of this kind and so it is inevitable that a few key words, phrases and quotations on my mind that might just as well apply to other works will have found their way into the text. However, it had been some time since I last heard Triadic Memories in its entirety (Philip Thomas's performance at the University of Huddersfield in October 2010) and I was surprised whilst listening to the piece again how much of the material seemed new or different to what I remembered. This may have been partly due to not having heard Takahashi's version from start to end before. I am also aware that transcribing one's experiences is not an ideal way to appreciate this music and that having to commit my observations to the page must have had an effect on my mode of listening. Perhaps the main reason, however, is that there is so much in Triadic Memories to remember (or rather to forget). The notes below are testament to the sheer incomprehensibility of this work through the intentional confusion of memory protention and retention over its extended time scale.

Through the process of retrospectively comparing my observations with the score, it has been interesting to observe how Triadic Memories contains the genesis of many of the procedural aspects adopted by Feldman in subsequent works, and in particular String Quartet II, where the constant interplay of mobile materials 
over long periods of time becomes integral to our understanding of the work. From my notes below it seems clear that a disorientation of sorts occurs quite early on in the work (some three minutes in), where, due to a process of octave transposition, the close proximity of pitches within the three note cells makes it unclear where one motif ends and the next one begins. (Catherine Costello Hirata also discusses this perceptual illusion in her perceptive article 'G Maybe-To G\#' (2005-2006, 383385). However, it is from page 16 onwards that the real perceptive disorientation that Feldman discusses takes hold. It is at this point (just under 20 minutes in the Takahashi version) that Feldman begins to bring back previously heard material. The repetition of these same ideas continues throughout the next third of the piece, sometimes repeating ideas exactly but most often with some kind of variation. In the final third of the work new materials are introduced that are subsequently repeated in much the same way and also include elements from earlier in the composition. The idiosyncratic use of notation does not always translate audibly from the score (grace notes suspended in the air or repeats that are placed in the middle of bars for instance) but instead seem to provide some kind of mnemonic reference for the composer through which the same materials can be repeated, varied or combined. The lack of visual clues adds to this disorientation and is further complicated by the consistency of the pitch materials themselves (an abundance of seconds, sevenths and diminished fifths) that negates any immediate sense of directionality or functionality.

Robert Henderson, following the British premiere of the work, described the piece as 'concerned with the shape of a leaf and not the tree' (1981). The following text very much expresses this viewpoint, focusing on the singular event, the solitary moment, through which form dissolves and scale opens up as real, experiential entity. One senses that Feldman discovered this for himself through years of composing and, no doubt, through listening to his own works. This act of discovery becomes something that we are invited to share in as a listener. This is not music that professes to provide answers but instead leaves us feeling enriched from the experience of listening. 
Quietly, persistently, an alternation of three-note figures

One figure $[G, G \#, D]$, and then the other $[B b, A, C \#]$

Each note has its own weight

Like Mondrian, 'not painting bouquets, but single flowers at a time' (Feldman 1985, 124)

Slightly irregular in periodicity but not entirely unpredictable

'...the human face: overall symmetry dominates, but the halves, whilst internally consistent are not exactly the same' (Glassie 1993, 671) The repeated minor third $[G, B b]$ in the high register, floating Pitted against the fog of the lower notes

Half-pedalled, distinguishable, but always slightly out of reach

Now a change in register as the highest notes descend by an octave The same figure now plotted in a different space but with the same slight irregularity

Feldman's notion of a 'crippled symmetry', imbued with a playful ambiguity These new notes, now considerably more foregrounded, step forward, assert themselves

Another registral shift as the lowest notes move up the octave, coming into focus, inhabiting the same space, becoming figurative, almost motivic No, they now appear as distinct voices, locked into a continuity of pitches Partial melodies conjoin and I no longer know where the patterning begins Does the sequence start with the highest note and move downwards or vice-versa?

It is difficult to tell; an Escher staircase, traversed in both directions

And now the pitches change $[G, G$ b,$F]$

Notes chosen seemingly for the way in which they hang, immobile in the air The rhythmic structure remains momentarily preserved and the patterning continues 
Rotations, a confusion of the auditory senses

The music suddenly blossoms, like an opening flower

We are in a different space

The logic of the preceding moment is broken

A rich texture emerges, dancing between registers

An abundance of dyads, chords and arpeggios play in quick succession

[In the score these passages are notated across three staves]

Feldman has made the leap, his faith in intuition restored

I give up the promise of a continuing process

The suggestion that the piece, up and running, will write itself, was an illusion

Feldman does not allow us time to ruminate on how this textural interplay relates to the processional temporal unfolding of the preceding moment - we are in a new space

Chords, patterns, unfolding sumptuously

Now single patterns, repeated several times, obsessively

Four times, five times? They seem to vary

For a moment the music feels replenished, figurative once more

Still displaying such an abundance of unresolved tensions, Feldman keeps us attentive to the moment

If the music is to let up then that time is still to come

Figures and more figures

Changing patterns that appear flitting and spacious

A sound-world harmonically and texturally reminiscent of Takemitsu's late piano works or perhaps Jasper Johns' cross-hatch patterns; Usuyuki, Dancers on a Plane

Takahashi's patterns are light to the touch, yet etched decisively

'She slowly paints, lightning-quick apparitions' (Paz 1990, 46) 
Vertical material now dominates and a new moment emerges

I feel, temporarily, like I have arrived somewhere, but where?

The music seems to have lacked the directional impetus to have taken me here

An absence of musical grammatology, teleology, rhetoric

Now more cross-hatch patterns and the moment becomes seemingly more spacious

Rivulets of notes, repeated four or five times

A dialectical interplay now opens between chords inhabiting different registral spaces and fleeting patterns

These feel familiar, or at least seem to contain semblances of the past

Backwards, forwards, I had failed to notice previously how much Feldman likes to alternate between two events

More figures that vary in harmonic content but always the same highest note A point of fixity on a traversed plane

Now, out of nowhere, a theme $[B, D b A \#, D]$

When we talk of figures it is in relationship to a ground

But here, unaccompanied - a figure without a ground

Each note is stated independently, serenely; Proust's 'incandescent body' Takahashi's touch - a reminder of what Feldman learnt from Madame Press

And from this comes a series of dyads, equally as sensuous to the touch Shifting in registration

This see-sawing effect goes on for some time - a theme, then dyads Feldman allows us to settle in the moment; to-ing and fro-ing We revel in the beauty of the moment, alive to the sound Like Beckett - always saying the same thing, backwards and forwards, in and out of shadows

Periodic, now a-periodic, saturated in hues 
I begin to see a spacious dimension opening up within the piece

A sense of wholeness through which the past does not beckon

It is becoming difficult to write or to describe the passing of events

Time seems to slow down

The sanctity of the moment

Feldman declares a space and invites me simply to listen

Now the remnants of this theme, and my memory involuntarily opens up

Is this presented too soon perhaps?

I do not wish to recall past events but to savour the moment

I remind myself that this past theme is now reinstated in the present

But this moment is fleeting and is now followed by a new event An irregular arpeggiated figure, like the patter of rain

Close registration this time; clouded hues of minor thirds and semi-tones Now high registration chords again and mid-to-low patterns

More ominous this time and even slower

Stretched out in time

Rising arpeggios, once again characterised by the same highest notes More patterns, figures, always figures

Now persistent, obstinate, repetitive

The theme, each note presented individually, reinstated with each successive moment

Takahashi's tone - Madame Press at the piano

This seems to mark a new point in time and with it a different sonic world I do not count the repetitions since this would leave a trace, suggest a path that points backwards

Somehow each sound seems like a new entity

How many times I hear each note I do not wish to know 
What purpose would it serve?

More broken textures, Takemitsu again

The single notes from the theme return and remind us of the beauty of touch

I anticipate a rising major third at the end of the melody but instead Feldman writes a chord

Momentarily I lost the moment, caught in anticipation

Now the theme, this time higher, half remembered Feldman consciously evokes memory

An interruption through the persistence of a chordal passage in the midregister

Its rhythmic periodicity and sense of contrary motion is clear and distinct I break from the past, its memory momentarily erased

Now a reminder - patterns again with repeated high notes

Followed by clusters once more, always persistent, repetitive

After some time, figurations, more patterns

Obsessively repeating, almost familiar

Patterns and more patterns, the weave of the Anatolian rug maker

But I am lost. I cease to understand the relationships between the events I am hearing

I must simply submit to the moment

Unknowingly, perhaps, I cope through forgetting to remember

What I experience is not an intellectual art but requires the discipline to listen

My listening begins when I leave my analytical mind at the door At the same time, Feldman is a realist; his art does not transport me to some fantastical realm -

Feldman is with me in the room, working, making those snap decisions 
that keep me alive to the moment

It is difficult to continue to write, to describe this ongoing process, and I now know why most analysis of Feldman's music stops after the first few pages of the score

What I am witnessing is the constant interplay or rotation of maybe four of five ideas; clusters, patterns, repeated dyads, triads. What else?

Back a few pages, now forwards, back a little more For me to describe these events over and over again seems redundant as an idea

I have been here before, looking back through the many pages of String Quartet II to find out where events re-occur What can I say of this constant teasing out of ideas?

I have studied the score to Triadic Memories but right now its details elude me

Again, the failure of memory. What do I remember?

A handful of notational images, distinct yet inter-related

But here, in this 'acoustic reality' of the moment these notational images are somehow less apparent

This visual identity, these figures that inhabit the mind, seem richer and more textured, perhaps?

I want to see the score but that is to trick the ear into believing Architectural, instrumental, spatial, three-dimensional Communicative, yet beyond the realm of actual visual portrayal

Where am I? Perhaps only a third of the way through the piece but already writing less of the particulars of each event

What I wish to avoid at this point is some kind of narrative - this, then this, then this

The stark reality is quite different; I am inside something large, vacuous, 
transformative

This does not follow this that follows this

Each moment feels individual, marked by the passage of time perhaps, but equally unique

The opening of the piece - some time event in the past that I am not asked to recollect

The ending cannot exist since it does not equate with the conditions of my presence

It is not something that can be wholly imagined right now since it is something that has not yet occurred

[Merleau-Ponty reminds us that the analogy of time as a river containing a temporal flow has its limitations from an experiential point of view since this pre-supposes a witness who was there at its inception, and will continue to be there through its successive flow to the present and on into the future (Merleau-Ponty 1962, 411). On the other hand, when listening to a piece of music it might be considered that we do bear witness to the successive unfolding of the events in the work and follow its marked progress through time. And yet, in the case of Feldman's music, we might say that Merleau-Ponty's phenomenological view still seems to bold true; this time is not a continuation of that time. Nor is it that time reinstated. Right now, listening to the constant re-ordering of materials, it does not even feel like I am revisiting the same places. Rather, these are unique places that become 'babitable' through an understanding of some of the characteristics of the previous places. It is, as Feldman has stated elsewhere, like re-acquainting yourself with someone you have not seen for some time - we speak of knowing the person but with the knowledge that this person has changed through the experience of their recent past. They are simply not the same person ...]

But I digress ...

What I am witnessing, presently, within this large, outstretched moment, 
is the alternation of two principal sets of materials:

The first comprises a single line with additional notes that flit and dance in quick successive leaps; the second, dyads that alternate between a mid and low range

This alternation, this coming and going, continues

An obsessive gesture emerges, repeated perhaps six or seven times

Now patterns previously heard again

But from which point in the past are they derived?

Are these the same pitch patterns or varied? Are the rhythmic profiles the same?

Does any of this really matter from an experiential perspective?

There are simply too many moments to keep track

And now, at a point when words fail me, Feldman introduces new material ...

High notes and low notes leap agilely onto mid-range chords

Pairings of chords again - first this, then that

Each two-chord progression proceeded by a pause, then repeated

Once again, my memory seems to be wiped clean

A sonorous line emerges amongst the flitting of grace notes, elegantly conceived

Now, once again, the to-ing and fro-ing

Dyads again, this time a more abrasive type of patterning

The event feels familiar and yet somehow obscured

Transformed by its immediate past

A mid-range pattern

Again, the hue, the abrash

What follows is new but does not come entirely as a shock

The previous pitches give way to a single-line melody

Again unaccompanied, simple to the touch

No octave displacement here, just simple notes, contingently placed 
A stark melody $[D b, C, D, C, E b$ etc. $]$ in the mid-range of the piano Stretching out in time, a line taken for a walk Then another new event - beautifully crisp, arpeggiated figures, reiterated again and again

Then the single-line melody

And the elegant arpeggios once more

The single-line melody returns again, this time in a new register

Octave shifts, reminiscent of the opening process

An indirect memory

But this is a new space

A brief dancing display of notes, simultaneously high and low

And now a surprise - a low tremelando passage

A rumble on a single chord, static, undefined

This moment becomes extended in time

The material feels uncharacteristic of Feldman

No, it is not the material that is uncharacteristic but the manneristic ('unfigurative') way in which Feldman presents it

A stranger in a room of figures

Will this return?

Where are we going? Where is the music taking us?

Stability is regained

Beautiful ripples that seem to emanate outwards against a silent backdrop And now motionless chords that stand as stationary objects

Repeated without deviation in pitch or register

The same chords, played over and over, as if placed in a room to be observed singularly

We have come so far to observe the beauty of such simple things 
Then repeated chords in various registers

Playful, colourful

Registration again

I sense the end of the piece. Why?

No, this is not the end.

But where are we?

Ripples again, figures, chords

Rotations that appear to look backwards and forwards

Everything against a white canvas

No pictorial depth, just surface

Mondrian's bouquets again, still life

Fixed chords, then ripples

Extended patterns

Motionless; Feldman suspends time in the air

More fixed chords, repetitious, solid to the touch

Now the single-line melody in a low registration

Pitch becomes almost obsolete against the hue

Except for single high notes that hover above, suspended in the air

A pause and then the melody again, now lower, stretched in time

Four notes $[C, D, E b, D b]$, remnants of the theme

Now the fleeting arpeggios, separated by silence

In a moment they are gone and with it the piece

No conclusion, no ending, just another opening - this time onto the world What can we draw from it all?

I cannot say, I am simply consumed by the silence from which the piece came 


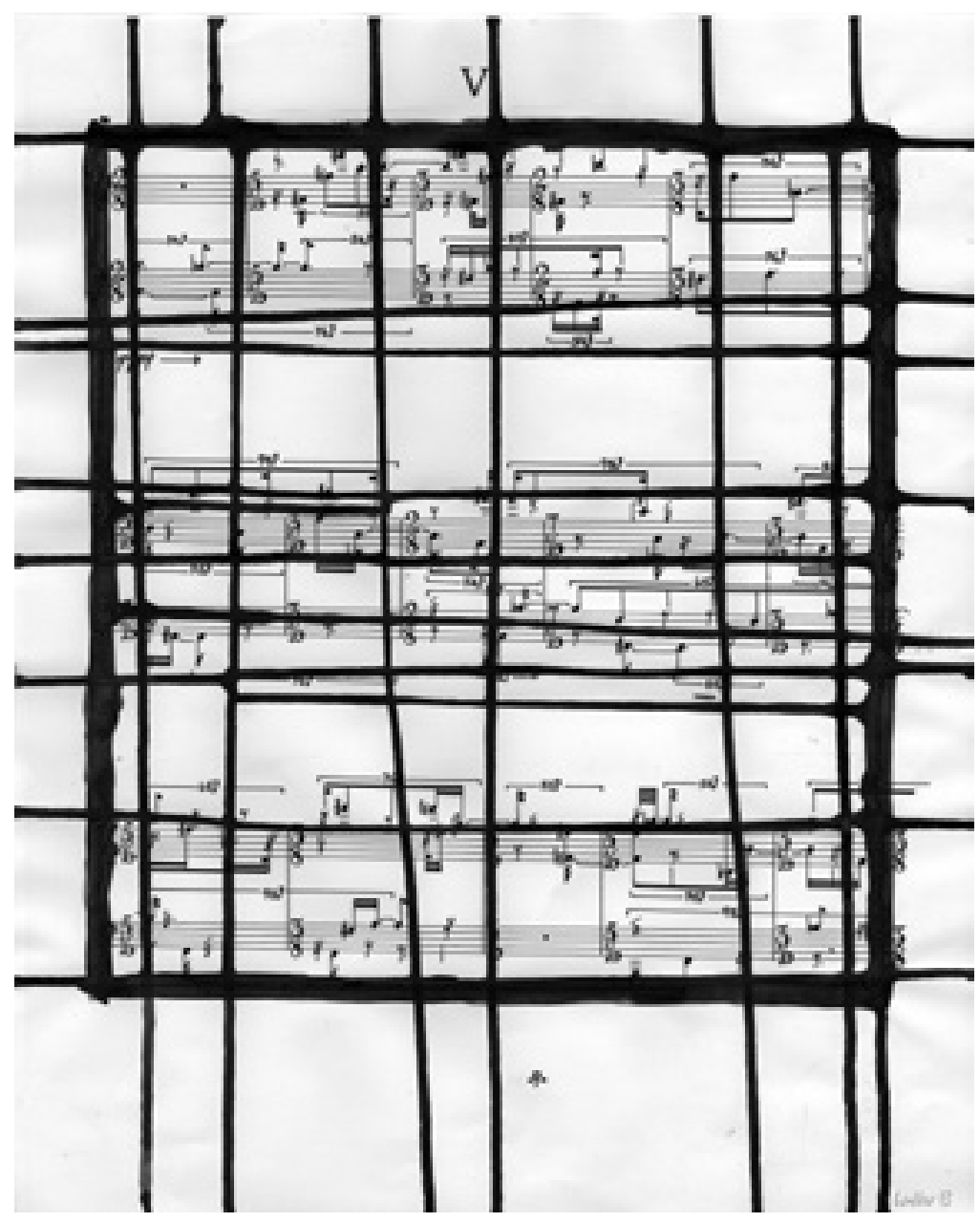

(C) Mike Walker 2013 